\title{
Identidades masculinas y moda en la pintura española del siglo XIX
}

\author{
Male identities and fashion in the nineteenth century \\ spanish painting \\ Carlos Javier CASTRO BRUNETTO \\ Universidad de La Laguna
}

Recibido: 23-III-2018

Aceptado: $11-\mathrm{VI}-208$

RESUMEN: En este artículo analizaremos varios retratos realizados por artistas españoles del siglo xix en los que la moda juega un papel primordial en la definición de la identidad masculina. Tanto la evolución de la indumentaria como de los gestos del rostro, la barba o el tipo de peinado, construyen formas de identidad masculina diferentes entre sí pero sometidas a la voluntad del artista o del retratado para afirmar su personalidad. Así pues, la moda se constituye como un método eficaz para estudiar el retrato como género artístico y la identidad masculina como un objetivo fundamental de la obra de arte.

Palabras clave: Arte; Pintura; España; Siglo xix; Moda; Identidad masculina; Hombre.

ABSTRACT: The aim of this essay is to analyse several portraits painted by Spanish nineteenth-century artists in which costume and fashion plays a key role in the definition of male identity. Costume's evolution and facial features, beard or hairstyle typologies, creates of different male identities which are submitted to the vision of the artist or the portrayed to reaffirm their personality. Thus, fashion becomes an effective method to study portrait as an artistic genre and masculine identity as a main objective in the work of art.

Keywords: Art; Painting; Spain; Nineteenth-century; Fashion; Male identity; Man.

\section{EL DISCURSO DE LA MODA EN EL GÉNERO DEL RETRATO}

Definir la identidad no es algo fácil, y analizar la identidad masculina, partiendo de la base de que existen maneras diversas masculinas de mostrarse, ser apreciado y aceptado por la sociedad, es un fenómeno de la cultura relativamente reciente, que anuncia ciertos cambios en la mentalidad española sobre todo a partir del nuevo marco político y social que supuso la transición iniciada en la década de los $70^{1}$. Lo percibimos en el escaso margen que la historiografía del arte ha dado a los estudios sobre identidad masculina ${ }^{2}$, ajenos a los de géne-

\footnotetext{
${ }^{1}$ El presente artículo se ha redactado como coordinador del Grupo de Investigación "Arte, Moda e Identidad" de la Universidad de La Laguna y como homenaje a mi querido y recordado amigo Fernando Galván

${ }^{2}$ Quizás el más destacado sea el estudio sistemático de Carlos Reyero sobre la identidad masculina y el arte
} Freile. 
ro, porque en los estudios de género se enfatiza el sujeto de análisis desde lo concreto (el hombre heterosexual, el hombre gay, el hombre transgénero), mientras que en este trabajo procuraremos mantenernos distante de esas apreciaciones para analizar una serie de retratos para valorar la construcción de la personalidad de una serie de hombres, tanto desde la perspectiva del retratado y el mundo que le tocó vivir, como desde la del pintor, con los recursos, formación e interés que conformaban su estilo.

Entre los textos teóricos más afortunados para comprender la definición de la identidad masculina, hemos elegido el de José Miguel García Cortés titulado Hombres de mármol, cuya aportación conceptual abarca diversos ámbitos, como la historia del arte, la psicología o la sociología. En cuanto a la relación entre el cuerpo humano, la identidad y la masculinidad, señala que: "el cuerpo es mucho más que lo que podemos observar (...). Su conformación debe ser leída como uno de los símbolos personales y sociales más importantes mediante el cual la identidad es creada, comparada y validada en el seno de una sociedad históricamente determinada y que, por tanto, su manipulación y conformación se refiere básicamente a la percepción por parte de los otros, de nuestra persona como un ser con un lugar reconocible en ese sistema cultural" ${ }^{3}$. Es decir, que la construcción de la identidad es creada en un tiempo y en una época, pero conforme se introducen otros parámetros culturales o temporales, su sentido puede variar. En ello intervienen los elementos simbólicos representados en cada una de las obras, la actitud personal de los retratados y los condicionantes de los pintores en su propio tiempo; sin embargo, existe un hilo conductor que nos

que, desde su primera edición en 1999, ha marcado este campo, siendo de gran utilidad porque supone un método de trabajo al servicio del investigador. C. REYERO, Apariencia e identidad masculina: de la Ilustración al decadentismo, Madrid, 1999.

3 J. M. GARCÍA CORTÉS, Hombres de mármol, Barcelona-Madrid, 2004, p. 12. permite abordar este tipo de estudios, que es la moda.

La moda no solo habla de la función estricta y explícita de la indumentaria; es, ante todo, un factor de reconocimiento social que constantemente se renueva en función de factores externos, como nuevas costumbres o hábitos sociales, la evolución en la confección de los tejidos, la búsqueda de otros complementos y aderezos, en definitiva, una constante investigación e innovación sobre sí misma y todo ello, producto de los limites sociales. Para Lourdes Cerrillo: "el vestido estará ligado a la vida mostrando su compromiso con la circunstancia específica, aunque la moda lo envuelva con una versatilidad transitoria, renovando constantemente su sistema de comunicación. Un sistema elusivo de reglas inflexibles, en el que lo normativo y la etiqueta se sustituyen por nuevos conceptos de libertad e innovación, manteniéndose, en el nuevo orden, expresivos principios de distinción o de elegancia, porque era preciso proveer a la moda de ciertas cualidades fijas y privativas" ${ }^{\prime 4}$.

Los ocho retratos masculinos que vamos a estudiar apuntan a que en la construcción del discurso de la moda que siguen los retratados se hallan muchas de las pistas para interpretar la forma de identidad masculina que esconden. Pero además de la indumentaria y su ajuste a la moda del momento, encontramos una segunda seña propia que se entrelaza: la mirada como foco del rostro.

El sociólogo y gran especialista en el significado de la moda, Nicola Squicciarino, indica que la mirada es una de los indicadores más potentes que envía el ser humano: "una mirada prolongada significa un interés más vivo por la otra persona en un sentido de tipo sexual, afiliativo o agresivo-competitivo" ${ }^{\prime 5}$. Bajo esta perspectiva, que aceptamos como una argumentación más que razonable sobre

\footnotetext{
${ }^{4}$ L. CERRILLO RUBIO, La moda moderna. Génesis de un arte nuevo, Madrid, 2010, p. 14.

${ }^{5}$ N. SQUICCIARINO, El vestido habla, Madrid, 2015,
} p. 27. 
el papel de la mirada como componente esencial de retrato, reconocemos que la unión del discurso de la moda junto con la fuerza de la mirada son los dos puntos que mejor expresan la identidad. En casi todos los retratos, el rostro está presidido por la mirada; también en los que hemos elegido al buscar la conexión con el espectador, sea de forma directa, o seductora. Pero es justamente en esa fuerza donde reside el poder de atracción. La moda refuerza la intensidad de la mirada, la hace más potente y eficaz.

Estos elementos convergen en un término de gran fuerza, aplicable a todos estos retratos: la elegancia. Ya Honoré de Balzac, en sus célebres artículos para el semanario parisino La Mode, a finales de 1830, exponía “¿Por qué iba a ser la indumentaria el más elocuente de los estilos si no se mostrara realmente al hombre en su totalidad; el hombre con sus propias opiniones políticas; el hombre con el texto de su existencia; el hombre hecho jeroglífico? (...) Por más que ahora ya todos vayamos más o menos vestidos de la misma manera, al observador no le costará mucho reconocer en una multitud, en una asamblea, en el teatro, en el paseo, al hombre del Marais, del fabourg Saint-Germain, del Barrio Latino, de la Chaussée d'Antin; al proletario, al comprador y al productor, al abogado y al militar, al hombre que habla y al hombre que actúa"6.

Balzac enfatiza los conceptos relacionados con la moda en el vestir y de elegancia como un lenguaje de afirmación personal que impregna cualquier nivel cultural por su carácter de elección personal que se diluye en el conjunto social. Así pues, en la ejecución de un retrato, la elección de la indumentaria que portará el retratado es tan importante como el deseo de trascender de la propia obra artística, profundizando en una construcción personal de elegancia. La periodista Lola Gavarrón, maestra en la interpretación de la moda como hecho social, refuerza estas ideas aplicadas a los años

${ }^{6} \mathrm{H}$. BALZAC, Tratado de la vida elegante, Madrid, 2011, p. 81 finales del siglo xx y en alusión al término elegancia señala que "respeta las reglas del juego con la actitud no de reproducir, sino de ir más lejos. No de perder, sino de ganar. No de fijar el modelo, en definitiva, sino de desbordarlo. Y abrir nuevos caminos"7. Y los retratos del siglo XIX que aquí abordamos recogen todos esos elementos: no reproducen modelos impuestos, la identidad se construye sobre la totalidad del individuo o de quienes contemplan la obra y señalan un espíritu de elegancia al trascender con la mirada y la indumentaria el marco temporal que es, en origen, el objetivo último de ese género artístico.

Una última cuestión introductoria sobre la importancia social de la identidad masculina a través del retrato y la moda es que el hombre, como identidad, lo es frente a su entorno social o familiar, ante la mujer como género, la esposa y los hijos, siempre o casi siempre, en una posición de fuerza y prevalencia. "Por estas razones, podemos decir que la masculinidad no se tiene, sino que se ejerce, y el poder es el eje central de su constitución y ejercicio. La identidad masculina nunca viene dada; por el contrario, se tiene que ir consiguiendo, afianzando y definiendo, siempre, en relación con los 'otros'. Más que realidad inalterable y fija, la masculinidad es un efecto de la cultura, una construcción, una performance, una mascarada"8. Siguiendo esa reflexión, la moda, el gesto del rostro o el peinado son señales evidentes del individuo, reconocibles por la sociedad y constituidos como una estrategia personal de comunicación. De esos recursos se vale el artista para proyectar hacia el presente y el futuro la identidad masculina en cuestión. A desentrañar esas claves dedicaremos los

${ }^{7}$ L. GAVARRÓN, La mística de la moda, Valencia, 2003, p. 44.

${ }^{8}$ J. M. GARCÍA CORTÉS, Op. cit., p. 42. Todo el discurso del autor, en lo relacionado con este libro, abunda en la necesidad de entender que la identidad del hombre lo es en cuanto a su oposición con la figura de la mujer, de la infancia y el resto de la sociedad. No existe identidad masculina sin identidad femenina sobre la que mostrarse. 
análisis de cada uno de los lienzos que nos ocupan, bajo la premisa de que la construcción del individuo a través de la moda es esencial para entender la pretendida trascendencia al pintar cada retrato.

\section{HOMBRES SINGULARES, HOMBRES A LA MODA}

El primer lienzo es el autorretrato que el pintor nacido en Tenerife, Luis de la Cruz y Ríos (Puerto de la Cruz, Tenerife, 1776-Antequera, Málaga, 1853), realizó hacia 1829/1830 durante un periodo en el que residió entre Madrid y Sevilla (Fig. 1). El artista se formó en la tradición tardobarroca en Canarias, aunque algunos de sus maestros ya se habían aproximado a los gustos clasicistas que llegaron a las islas en el último cuarto del siglo. Gracias a sus contactos llegó a Madrid en 1815 y hasta 1829 ocupó el puesto de pintor honorario de cámara de Fernando VII, empleándose especialmente en el puesto de miniaturista, y contó con el apoyo del primer pintor de cámara, Vicente López, para obtener el cargo de pintor de cámara, es decir, con sueldo, un sueño que nunca se realizó ${ }^{9}$. No obstante, pintó numerosos retratos regios y en todos se muestra como un profundo conocedor del gusto neoclásico que se respiraba en la corte madrileña y que se manifiesta en la composición, estilo y color de sus lienzos, prestando especial atención a las proporciones y gestos de los retratados. También destaca la veracidad del lenguaje de la moda, así como el mobiliario pintado, predominando el gusto imperio. Es lógica su predilección por el detalle, atendiendo al dominio del "género" de la miniatura. Sin embargo, lo que nos interesa de esta obra verdaderamente genial es la busca sin ambages de su identidad como pintor y como hombre moderno. El lienzo nos muestra el estudio del pintor compuesto por dos salas contiguas, y un fondo de paisaje, todo en punto de fuga. En primer plano, el artista, con una

${ }_{9}^{9}$ A. RUMEU DE ARMAS, Luis de la Cruz y Ríos, Biblioteca de Artistas Canarios nº 33, Islas Canarias, 1997, pp. 90-91. pluma en mano y cuadernos de dibujo apoyados sobre la pierna, está acompañado a su izquierda por una mesita en la que descansa la paleta de pintor y los pinceles y a su derecha un caballete montado con un cuadro, extraordinario, del rey Fernando viI, rodeado de mobiliario estilo imperio, señalando a la diosa de las artes, Minerva, bajo un templete circular de gusto clasicista. Viste un traje de dos piezas en seda amarilla, zapatillas rojas carmesí, camisa abierta y el pelo desordenado al estilo directorio y con grandes patillas, al gusto de la época.

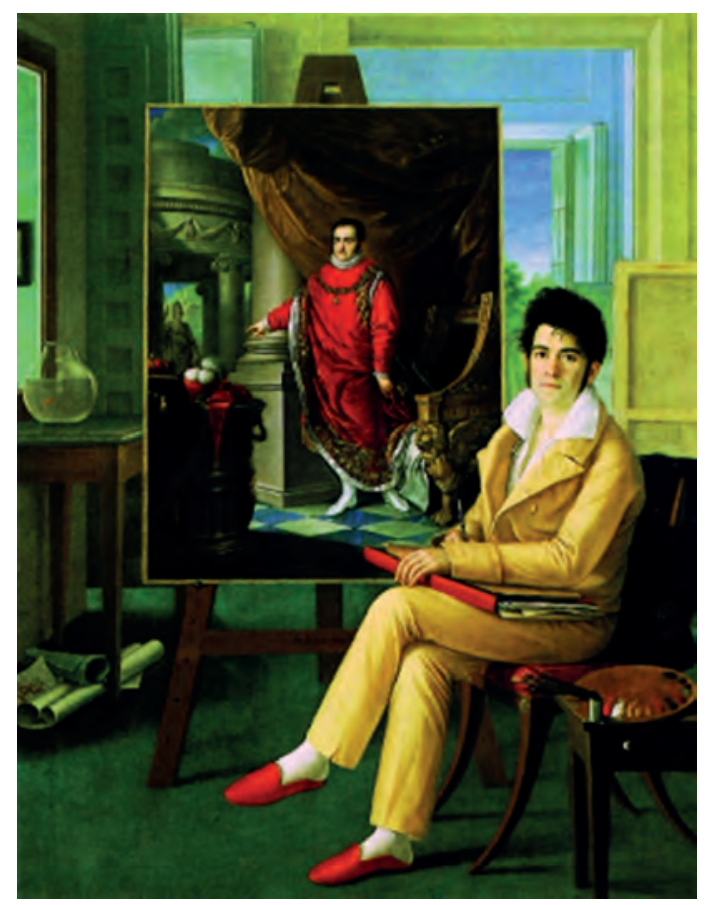

- Fig. 1. Luis de la Cruz y Ríos. Autorretrato. 1829/1830. Colección particular, Madrid. Foto cedida por Gaviño de Franchy Editores.

La historiografía del arte no comprendió bien el mensaje del artista a través de la indumentaria. Para Hernández Perera, tras valorar muy positivamente la compleja composición del cuadro, la calidad indudable en las proporciones y pericia en el género del retrato al tratarse de un cuadro dentro del cuadro, destaca que la indumentaria tiene "falta de verdad en las ropas" y "la pobreza de la estancia, del mobiliario y del atuendo da verdadero testimonio de sus estrecheces 
de artista bohemio y aventurero"10. Otro gran investigador canario, Antonio Rumeu de Armas, señala que "el pelo alborotado y las largas patillas son muy significativas. El artista aparece sentado, con un extraño indumento de faena: camisa blanca abierta con grandes vueltas; chaqueta y pantalón amarillos y babuchas rojas"11. Estudios posteriores continúan destacando muy positivamente este autorretrato, por ajustarse al contexto histórico y artístico de su épo$\mathrm{ca}$, aunque sin percibir la trascendencia en la forma de vestir ${ }^{12}$. Otras referencias sobre este lienzo se han producido en los últimos años, apuntando que la esencia del lienzo no era una cuestión de estrecheces económicas o la simple casualidad, sino de "una posición estética, netamente elegante y dandi, una forma escogida de ser representado como un hombre y pintor que está a la moda francesa en términos de ropa interior o de andar por casa"13.

Consideramos que la clave para interpretar ese autorretrato está, justamente, en la indumentaria. Es obvio que fue bien pensada, escogida con mimo y representada con rigor. El pintor buscaba reforzar su

${ }^{10} \mathrm{~J}$. HERNÁNDEZ PERERA, “Los retratos reales de Luis de la Cruz y Ríos", Anuario de Estudios Atlánticos, no 1,1955, p. 239. Este gran historiador del arte rechaza ese aspecto del cuadro por entenderlo escasamente acorde a la manera en la que el pintor retrató siempre a sus personajes, adecuados a la moda y etiqueta de la época. En realidad, todo su texto da a entender que no comprende cómo este notorio artista da una imagen personal tan pobre.

${ }^{11}$ A. RUMEU DE ARMAS, Op. cit., p. 128. Cuarenta y dos años después, Rumeu continúa destacando este autorretrato como una de las obras más soberbias del artista, pero muestra una profunda extrañeza en torno a la indumentaria que escogió para inmortalizarse.

${ }^{12}$ M. R. HERNÁNDEZ SOCORRO, "Rostros del ayer. Apariencias de presente: el retrato del siglo XIX en Canarias", en J. ALLEN (com.), Rostros de la Isla. El arte del retrato en Canarias [1700-2000], Las Palmas de Gran Canaria/Santa Cruz de Tenerife, 2002, p. 40.

${ }^{13}$ C. CASTRO BRUNETTO y D. MARTÍN LÓPEZ, “Elegantes, casi dandis, en la plástica canaria (18001950)", Estudios Canarios. Anuario del Instituto de Estudios Canarios, no 58, 2014, p. 109. identidad. Pero la identidad, a lo largo de la vida, muta, se mimetiza con las circunstancias del momento, con las exigencias del entorno. Hemos de entender este retrato en su contexto, 1829/1830. En esos años, Luis de la Cruz intentaba, sin conseguirlo, que el rey le confirmase en el cargo de pintor de cámara. Pero en aquel momento, Europa iniciaba una revolución política marcada por el auge de la burguesía, a punto de que se produjesen en París los acontecimientos de 1830 que contagiarían de un nuevo espíritu y una nueva estética al hombre moderno al que se refería Balzac. Madrid no escapaba de la influencia parisina y un hombre que quisiese ascender debía mostrarse moderno. La imagen en el vestir que nos ofrece Cruz es verdaderamente osada, aunque contraste con su mirada algo melancólica, tal vez expresando la frustración personal por un trabajo no alcanzado y potencialmente brillante para un individuo inclinado hacia una nueva estética.

Se muestra con un traje de dos piezas de chaqueta cruzada y pantalón en amarillo pálido, una camisa abierta sobre el pecho de amplio cuello y zapatillas de cuero rojo. Estas ropas demostraban ante todo intimidad, son piezas de usar entre amigos, en casa, pero esa moda tan al gusto dandi, fue importada de Inglaterra hacia $1820-1830^{14}$; nos sorprende la ligereza del vestuario, en el que se sugieren sedas en el traje de dos piezas y fino algodón para la camisa. Pero más arriesgado aún es el empleo de zapatillas en una obra donde el artista se representa junto al rey. Con ese calzado hogareño ¿quería ofrecer una imagen de cercanía inusitada con el monarca? Nunca lo sabremos, pero la selección de la vestimenta habla por todo lo que él calla.

Por esas mismas fechas, el pintor sevillano Antonio María Esquivel (Sevilla, 1806-Madrid, 1857) pintó un espléndido retrato del marqués de Bejons, que se guarda

\footnotetext{
${ }^{14}$ Véase P. ÁLVAREZ-QUIÑONES SANZ, Dandis, príncipes de la elegancia, Junta de Castilla y León, 2013, pp. 106-113.
} 
en el Museo de Bellas Artes de Sevilla (Fig.2). Del personaje no conocemos datos y sobre el lienzo, Bernardino de Pantorba ${ }^{15}$, autoridad y cita obligatoria por la historiografía del arte en lo que a Esquivel se refiere, solo indica que hacía pareja con el de su esposa y que ambos fueron donados en 1944, entre un grupo numeroso de obras de Esquivel, a la Real Academia de Santa Isabel de Hungría de Sevilla por el matrimonio formado por Andrés Siravegne y Jiménez y Caridad Lomelino y Regio, naturales de esa ciudad pero residentes en Madrid ${ }^{16}$. Pensamos que sería ejecutado en la década de 1840 porque estilísticamente se aproxima a los numerosos retratos efectuados en la capital durante esos años y porque la donación formaba parte de

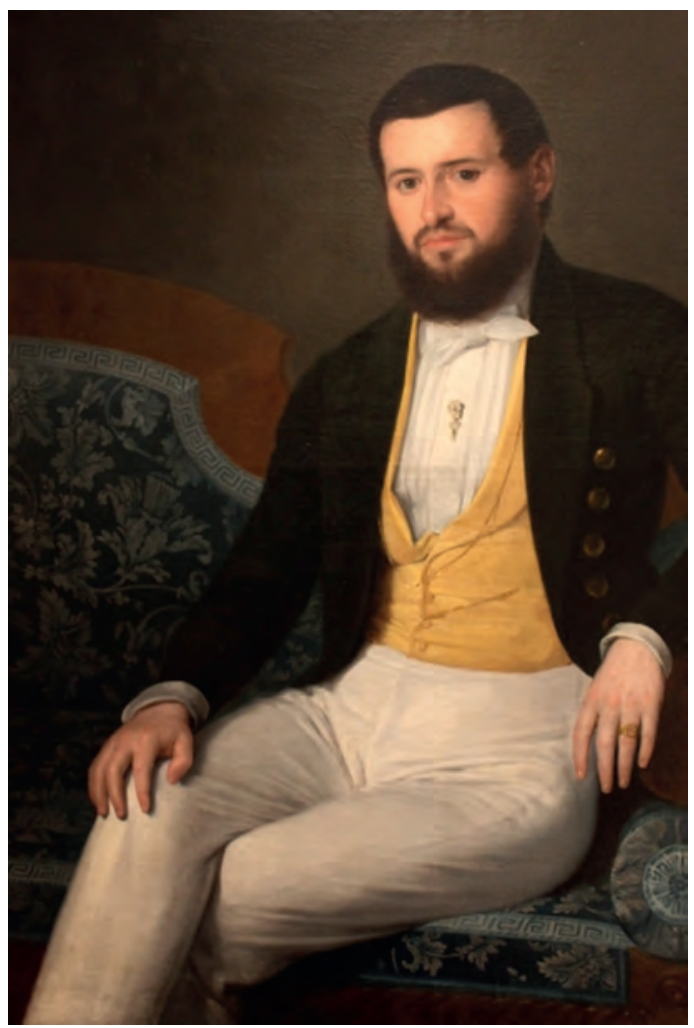

- Fig. 2. Antonio María Esquivel. Retrato del marqués de Bejons. Ca. 1840. Museo de Bellas Artes de Sevilla. Foto del autor.

\footnotetext{
${ }^{15}$ Recordemos que es el pseudónimo escogido por el historiador del arte José López Jiménez.

${ }^{16}$ E. de PANTORBA, "Antonio María de Esquivel", Arte Español. Revista de la Asociación Española de Amigos del Arte, año XLII. XVII de la $3^{a}$ época, T. XXII, 1958, pp. 165-171.
}

una colección de pinturas suyas que se hallaba en Madrid.

El artista, un hombre de su tiempo, romántico por definición personal y estilo, alcanzó su madurez en esa década, cuando residía en la Corte, aunque para él la fuente de la belleza del gran arte al que aspiraba residía entre los grandes maestros sevillanos del barroco ${ }^{17}$. No obstante, se sumó al gusto romántico como forma de expresión estética, y por mostrar ambas influencias fue considerado como un maestro "templado". Esa preocupación y dignificación del retratado se aprecia en este lienzo, que nos muestra a un hombre seguro de sí mismo, pero no carente de una cierta melancolía, acorde con el sentir romántico en el que la confianza se expresa incluso con moderación. Lo singular es la vestimenta que luce el retratado, diferente de otros muchos lienzos del mismo artista y periodo; de hecho, la composición de la indumentaria está en la frontera entre las últimas influencias dandis, como se percibe en el estrecho pantalón, en el que se insinúa un tejido de algodón, el chaleco en tono amarillo pálido y prendas más cercanas a la influencia inglesa contemporánea que triunfaban por toda Europa, como la levita con botonadura generosa dorada, y una camisa blanca de pechera plisada, con una condecoración sobre la franja central y el cuello cerrado por una corbata de lazo.

La indumentaria revela tres colores para pintar al marqués, algo singular si consideramos que la levita y el pantalón negro se imponían poco a poco; así pues, el retratado está en el borde entre el viejo dandismo de comienzos de siglo y la moda. Esto podría indicar dos cosas, o bien que Bejons gozase de una personalidad que se expresase en la elección de las prendas para su retrato, o bien que Esquivel seleccionase la ropa basándose en repertorios de prendas masculinas al margen de la moda del momento. Sea como fuere, el marqués de Bejons será recor-

\footnotetext{
${ }^{17}$ G. PÉREZ CALERO, “Consideraciones estéticas en torno a la obra del pintor Antonio M. Esquivel", $\mathrm{La}$ boratorio de Arte, no 24, 2012, p. 530 .
} 
dado como un hombre joven de gran personalidad, confirmada con su barba cuidada en su formato redondeado, y una forma de vestir cuidadosamente escogida para reforzar una identificación plena con una estética original y distinguida. El conjunto de este retrato queda reforzado por la extraordinaria capacidad del artista para reflejar el canapé fernandino sobre el que se sienta, de seda azul y estampados florales grises, así como la cenefa de pasamanería en greca, lo que revela que el pintor estaba perfectamente familiarizado con la estética del mueble y su representación pictórica, tanto en los tejidos como en las calidades de las maderas ${ }^{18}$.

Luis Ferrant y Llausás (Barcelona, 1806-Madrid, 1868), pintor barcelonés formado entre Madrid y Roma, continúa siendo un artista relativamente poco conocido, a pesar de haber asumido los valores del pleno romanticismo, tanto en la genealogía del paisaje como en el concepto del retrato, animado sin duda por los contactos y experiencia acumulada en la capital italiana donde estuvo aprendiendo y pintando, junto con su hermano Fernando, entre 1830 y 1842, gracias a la protección dispensada por el infante Sebastián Gabriel de Borbón y Braganza (Fig. 3). Proveniente de una larga dinastía de artistas ${ }^{19}$, centró, perceptiblemente, el interés de sus retratos en la fuerza del rostro, enfatizando la mirada, y en la busca constante de la conexión entre el lienzo y el espectador, tal vez deseoso de que se captase el genio o el alma del personaje. Las calidades de Ferrant son apreciables, aunque no siempre consiguió que el equilibrio de las proporciones fuese el más adecuado. De lo que no cabe duda es de su interés por la indumentaria.

${ }^{18}$ No es coincidencia que desde 1827 se iniciasen las exposiciones y premios para la ebanistería y las artes decorativas en Madrid. A. LÓPEZ CASTÁN, "Las exposiciones públicas de los productos de la Industria Española y las artes decorativas en el Madrid fernandino", Anuario del Departamento de Historia y Teoría del Arte de la Universidad Autónoma de Madrid, no 3, 1991, pp. 126-128.

${ }^{19}$ M. FUENTE MUÑOZ, "Aportaciones documentales sobre una familia de artistas: los Ferrant", Goya. Revista de Arte, no 285, 2001, pp. 357-358.
De 1845 data el retrato que pintó de su hermano Fernando, también pintor, siendo la moda una clave para su lectura.

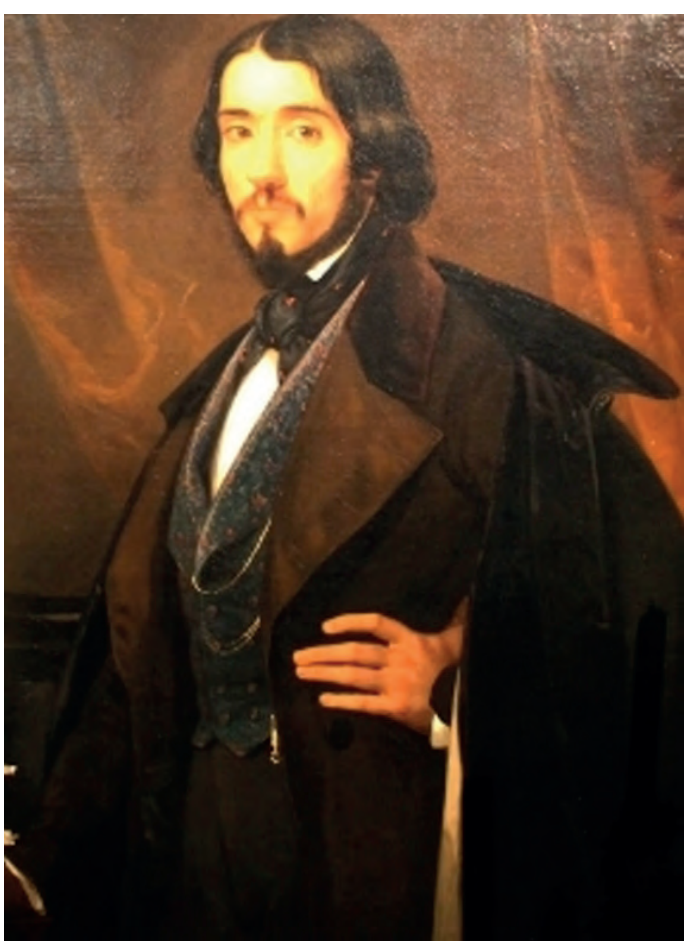

- Fig. 3. Luis Ferrant y Llausás. Retrato del pintor Fernando Ferrant y Llausás. 1845. Museo del Romanticismo, Madrid. Foto del autor.

No elude la peculiar característica física de su hermano, el estrabismo de un ojo, aprovechado para conferirle carácter, pero es la forma de vestir la que nos informa sobre la elegancia y distinción de Fernando. Usa un traje moderno, de pantalón y levita de tonos marrones de sarga de lana, la levita de amplias solapas cubierta en el cuello por lo que parece una piel de visón de pelo muy corto. Ese tipo de levita y cuello es aún una reminiscencia de la elegancia del dandi del primer cuarto del siglo, que establecía la diferencia en los pequeños detalles. Bajo el traje usa un chaleco de seda floral con doble botonadura, cruzado por un reloj de oro, que solo apreciamos por la cadena y parte del colgante, detalles del lujo de otro tiempo que aún no habían sucumbido al imperio del color negro que estaba a punto de imponerse. El stock o cuello postizo añadido a la camisa, alto y rígido, le permite el uso de una corba- 
ta verde estampada con pequeñas flores en tonos naranja, de exquisita seda, anudada en lazo con nudo central prominente. Sobre las espaldas y levemente recaído sobre los hombros, se ha pintado la prenda de abrigo de moda, un redingote negro de amplio cuello levantado, aunque semidoblado, que hacia 1840 había dejado de ser una prenda para montar a caballo para convertirse en la preferida para usar en actos sociales. Finalmente, su indumentaria se remata con una pareja de guantes de cuero en color tostado que porta en la mano derecha.

Esta forma de vestir, en la frontera entre los tiempos del dandi y los rigores del color negro que se impondrían a mediados del siglo, hemos de entenderla como la reivindicación del individuo y del artista, de un homenaje de Luis a su hermano Fernando como un hombre de gusto, con amplios conocimientos sociales y profesionales, refinado y audaz, características que definen a la perfección el pensamiento romántico.

Analizaremos ahora dos lienzos de sendos artistas que presentan la identidad masculina a través del retrato, no tanto a través de la indumentaria, sino de la comunicación del rostro como espacio simbólico (Fig. 4). El pintor gaditano Francisco Javier de Urrutia (Cádiz, 1804-1869) firmó en 1841 un lienzo en cuya parte trasera indica: "Este retrato es de José Robles/gastador cumplido del regimiento/ provincial de Murcia. Nació en Espinardo/ el año 1816/Cádiz 12 de marzo de 1841/Javier de Urrutia/Gaditano pintor". Dos años después publicaría su trabajo artístico más conocido, la Descripción histórico-artística de la catedral de Cádiz. Pero lo que ahora nos ocupa es este lienzo conservado en el Museo del Romanticismo de Madrid. Desde el punto de vista artístico apreciamos que la fuerza del retrato reside en la capacidad para captar la luz y proyectar la viveza del rostro, especialmente de la mirada, así como en el verismo del uniforme militar que luce, del regimiento de gastadores; sin embargo, la proporción del cuerpo no parece acompañar a la cabeza, aunque no sabemos si se trata de un problema de dibujo o el re- sultado intencionado de aprovechar esa circunstancia para aumentar el volumen de las charreteras, la mochila y la bayoneta. Pero, sin duda, la barba es el elemento de identidad por excelencia, una barba llena que no es casual, puesto que en ese formato, asociado con un cierto descuido y a los trabajos militares más pesados, era identificada como el elemento absoluto de la virilidad en la Europa del siglo xIx. Según señala Kevin Clarke, la barba hacia mediados del siglo quedó ligada al prestigio del militar que retorna de las numerosas guerras ${ }^{20}$.



- Fig. 4. Francisco Javier de Urrutia. Retrato del gastador José de Robles. 1841. Museo del Romanticismo, Madrid. Foto del autor.

La barba actúa en este caso como catalizador de los valores humanos y profesionales del gastador José Robles; como señala Squicciarino, es el elemento que busca el feedback para que se decodifique el mensaje a falta de un lenguaje verbal ${ }^{21}$. Para García Cortés, la barba funciona como un factor preciso para identificar este modelo de identidad masculina, pues los elementos "que han permitido crear el cuerpo del hombre

${ }^{20} \mathrm{~K}$. CLARKE, Beards, an unshaved history, Berlin, 2015, p. 172.

${ }^{21}$ N. SQUICCIARINO, Op. cit., p. 19. 
musculoso y potente como representación ideal de la masculinidad y que representa el poder, la rigidez y la invulnerabilidad" están presentes en este lienzo, es decir, las armas, el uniforme y la fortaleza de la mirada, como complementos perfectos a esa barba que quiere decirlo todo sobre el carácter recio y masculino del militar Robles, quintaesencia del soldado romántico del pleno siglo XIX ${ }^{22}$. En cierto sentido, podría decirse que en la percepción cultural de esa época, la barba sería comprendida casi como un atributo fálico; así, todos los recursos compositivos del lienzo actúan como fuerzas centrípetas hacia ella, acentuados por el empleo de un fondo neutro poco común en el retrato romántico hacia 1841, menos aún en la escuela gadi$\operatorname{tana}^{23}$, tan próxima a la sevillana, donde el constante recuerdo del concepto teatral barroco definía el estilo (como hemos visto en el caso de Esquivel), siendo los complementos compositivos una necesidad indisociable al género del retrato.

Un segundo lienzo refuerza todas estas ideas. Nos referimos al Autorretrato del pintor asturiano Dionisio Fierros (Ballota, Cudillero, 1827-Madrid, 1894), propiedad del Museo de Bellas Artes de Asturias, en Oviedo (Fig. 5). Se conoce bien su biografía, y por ello sabemos que su solidez formativa transcurrió en Madrid en el entorno de la Academia de San Fernando y trabajando en el taller de José de Madrazo y luego en el de su hijo Federico ${ }^{24}$. Se garantiza, por tanto, la asunción de los ideales románticos presentes en este lienzo firmado y datado en 1866. Como en el caso de la pintura de Urrutia, Fierros ha optado por un fondo neutro y para desentrañar su imagen es fundamental la fecha en la que se ejecutó. Por esos años, ya se había establecido la relación entre Fierros y Santiago de Compostela, adonde se trasladó unos años

${ }^{22}$ J. M. GARCÍA CORTÉS, Op. cit., p. 16.

${ }^{23}$ A ese respecto véase A. del BANDA Y VARGAS, "El academicismo en las artes figurativas gaditanas", Archivo Español de Arte, no 226, 1984, pp. 129-140.

${ }^{24}$ J. VILLA PASTUR, “Dionisio Fierros Álvarez", en Pintores Asturianos, Oviedo, 1973, T. IV, pp. 21-158. con el fin de pintar a miembros de la burguesía local, al igual que había acontecido con la asturiana y madrileña. De esos años se han destacado tres características: la de mostrar en su obra el aprendizaje tomado de Federico de Madrazo, con gran precisión en el dibujo, linealidad y cuidado en la representación de la psicología del personaje, el empleo de una pincelada más suelta y empastada y acercarse a temas y asuntos propios de la tierra a la que pertenecen sus retratados, fuese Asturias o Galicia ${ }^{25}$.

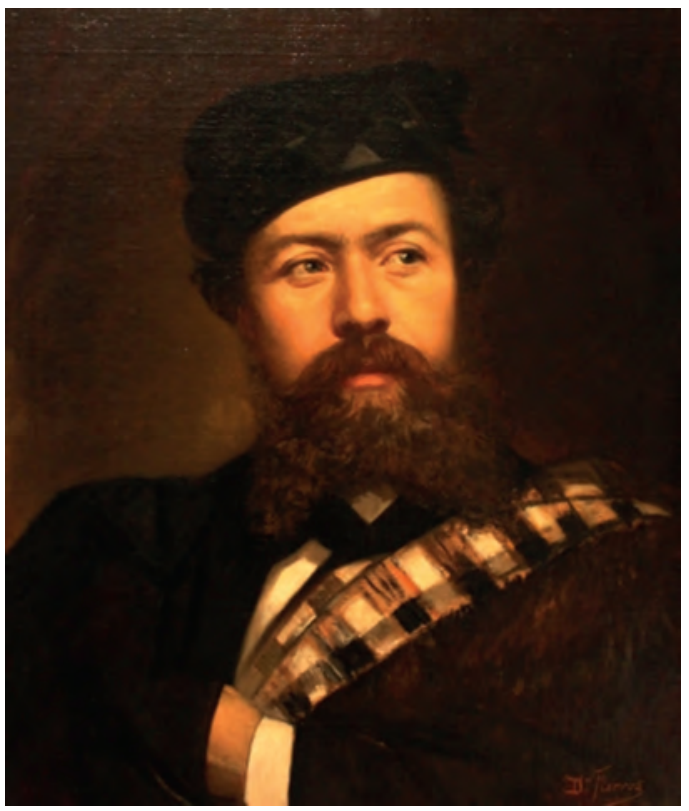

- Fig. 5. Dionisio Fierros. Autorretrato. 1866. Museo de Bellas Artes de Asturias. Foto del autor.

Al analizar esta pintura desde la perspectiva de la historia de la indumentaria como disciplina artística, quedamos impresionados por la forma en la que ha querido inmortalizarse. Lo ha hecho en clave un tanto enigmática en cuanto a la selección de sus ropas. Lo destacado no es el traje, que imaginamos de dos piezas, porque en realidad no lo pinta, pero sí que muestra una corbata en seda azul muy oscuro o negra y apenas insinuada, cruzada bajo el cuello de la camisa. Lo singular es la prenda que le cu-

${ }^{25}$ D. RODRÍGUEZ PAZ, "Dionisio Fierros, pintor burgués", Revista da Faculdade de Letras. Ciências e Técnicas do Patrimônio, Vol. IX-XI, 2010-2012, pp. 114-115. 
bre el cuerpo. Se trata de una capa que más que apoyada sobre los hombros, parece algo terciada, desde luego una forma de llevarla muy irregular, con la esclavina de piel de zorro unida al paño de lana del capote por una franja, supuestamente de lana, a cuadros negros, grises, blancos y burdeos. Cubre su cabeza con un extraño gorro, que a nuestro juicio parece apuntar una mezcla de lana y seda; quizás sea la pieza más extraña de toda su indumentaria y a la hora de interpretarla, nos recuerda a la montera tradicional asturiana, que no deja de ser una evolución sofisticada de la colocación de un pañuelo sencillo de lana o algodón para cubrir la cabeza y abrigarla de la meteorología.

Diego Rodríguez Paz, investigador de este artista, ha apuntado una posible influencia de la indumentaria y pintura inglesa o francesa en este autorretrato ${ }^{26}$. Podría ser, pero creemos que más que buscar antecedentes en obras artísticas foráneas, aproximarnos a la mentalidad española del momento es esencial, y tal vez ahí esté la clave. Y el momento es 1866, como ya habíamos apuntado. Por entonces, el regionalismo, es decir, destacar los valores locales, inspirarse en el folklore y en cualquier manifestación de la cultura popular está "de moda" y ese gusto estético lo atraviesa todo, de la pintura a la música y, por supuesto, la literatura; no obstante, sería un fenómeno que no tendría que ver con el "majismo" de comienzos del siglo, sino con una progresiva incorporación de esa indumentaria al vestir moderno, como la capa española. En ese sentido, creemos que Fierros emplea elementos de la indumentaria popular asturiana (y de otros lugares) como el capote y la montera, para adaptarlas a este autorretrato y reivindicarse, más que como asturiano, como hombre del norte de España, e incluso sería posible que pretendiese introducir ideas novedosas en el mundo de la moda. Porque en este cuadro vemos moda, moda en el vestir, moda en

${ }^{26}$ ÍDEM, "El pintor ante su imagen: una aproximación a la obra de Dionisio Fierros a través de sus autorretratos", en Mirando a Clío. El arte español espejo de su historia, Santiago de Compostela, 2012, pp. 579-580. el actuar. Y para mostrarse como amante de la moda, su imagen queda reforzada por una barba llena, organizada en dos puntas, y una mirada firme que denota confianza y seguridad sí mismo. Claro que cabría preguntarse si este autorretrato es un caso aislado o en sus otros autorretratos varía la actitud. Y la respuesta es clara e indiscutible. Cada autorretrato posterior es una lección de moda, de busca de una identidad masculina definida a través de la elección de las ropas, complementos y cómo emplearlos para mostrar imágenes siempre distinguidas y novedosas. Dicho de otra forma, la identidad del artista se manifiesta de forma clara a través del lenguaje de la moda. Así pues, podríamos aproximar a Dionisio Fierros al concepto del dandi, en el sentido de que pretende crear una imagen de sí mismo muy distinguida, es decir, que persigue sobresalir del resto de sus paisanos por medio de una indumentaria original, diferente, singular, empleando atributos de la cultura dandi, como esa gorra original, aunque el dandismo conceptual ya se hubiese extinguido en la segunda mitad del siglo.

Otro retrato extraordinario desde la perspectiva de la historia de la moda llama nuestra atención. Se trata del efectuado al joven pintor Pedro Ximénez Mazzuco, por Pedro Martínez de la Torre (Jaén, 1847-Zaragoza, 1915) y conservado en el Museo de Jaén (Fig. 6). Eva Galán lo considera uno de los grandes retratistas jienenses, tal vez por su dominio del género dentro del concepto academicista, dotando de profundidad y equilibrio a las composiciones ${ }^{27}$. A este dato añadimos que a partir del estudio del lienzo que nos ocupa, podemos afirmar que es uno de los pintores más innovadores en la creatividad del retrato a partir de la moda, pues la manera en que viste a su compañero Pedro Ximénez Mazzuco, en la década de 1870, es de una modernidad alejada por completo de las maneras habituales al concebir la identidad masculina. El interesante trabajo de

${ }^{27}$ E. V. GALÁN, Pintores del Romanticismo andaluz, Granada, 1994, pp. 238-239. 


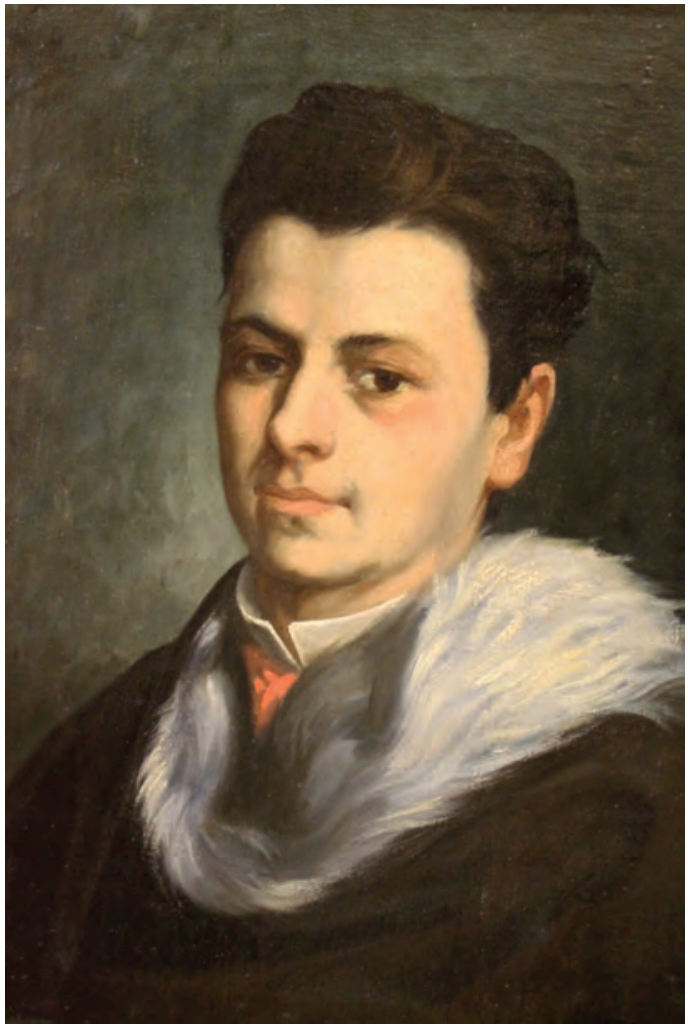

- Fig. 6. Pedro Martínez de la Torre. Retrato del pintor Pedro Ximénez Mazzuco. Ca. 1870. Museo de Jaén. Foto del autor.

Sousa Congosto analiza, en general, la historia de la indumentaria en España, dedicando un capítulo, claro, al vestir del hombre en el siglo XIX, y señala de forma concisa los hábitos masculinos, destacando la evolución de la levita hacia el traje y del redingote hacia el abrigo contemporáneo ${ }^{28}$. Pero ni este historiador ni otros muchos han reflejado retratos como el de Fierros o el de Martínez de la Torre-tampoco era su objetivo-, donde el artista figura a sus personajes como revolucionarios de la moda. En el caso que nos ocupa, el modelo, sobre un fondo neutro de pincelada larga y ligeramente empastada, viste camisa blanca con cuello stock, es decir, alto hasta la altura de la nuez, sobre el que aparece lo que deducimos un chaleco en un tono amarillo pálido, reminiscencia del aprecio por ese color, que ya hemos identificado en la moda española. Pero lo singular es que la prenda

${ }^{28} \mathrm{~F}$. de SOUSA CONGOSTO, Introducción a la historia de la indumentaria en España, Madrid, 2007, pp. 184190. que cubre el cuerpo es una capa verde oscuro con ribeteado generoso de piel de zorro blanco que constituye el eje absoluto del cuadro, tratado con un primor y una perfección que solo puede venir del contacto frecuente del artista con este tipo de pieza.

Analizando la historiografía del arte sobre este artista para conocer mejor su formación, hemos encontrado un trabajo que aporta la clave. Lo ofrece Carmen Eisman Lasaga, cuando informa de que en la década de 1870, y durante una larga estancia en Roma, Martínez de la Torre pintó con Mariano de Fortuny y Marsal (1838-1874). Tanto el padre como años más tarde su hijo, Mariano de Fortuny y Madrazo ${ }^{29}$, fueron verdaderos maestros en la representación de la indumentaria y el gusto por el vestir. La elegancia y el exotismo, constantes en la pintura de Fortuny, fueron estímulos visuales para el pintor jiennense, $y$ tal vez estuvo en contacto con prendas de ropa singulares fuera de los convencionalismos que circularían en torno a la familia Fortuny.

Ese acopio de experiencias se volcó en este cuadro por la forma de vestir relajada e innovadora que se suma al espíritu del joven pintor retratado, reforzada por un rostro suave y un pelo sin artificios, con un suave tupé, para agradar al espectador y comunicar el buen gusto de un espíritu refinado. James Laver destaca, refiriéndose a la moda inglesa en los años centrales del siglo XIX, que la gran novedad sobre las décadas anteriores, es que la moda masculina en la que se imponía la levita y el color negro provocaba "la desaparición de la extravagancia y del color en la ropa masculina" ${ }^{\prime 30}$. Pues bien, este cuadro demuestra que en la España que encaraba el último cuarto del siglo existían pintores y modelos dispuestos a la transgresión

${ }^{29}$ Mariano de Fortuny y Madrazo es, sin duda, el primer gran diseñador de moda de España, aunque bajo la influencia francesa de los grandes modistos de comienzos del siglo XX. Véase G. de OSMA, Mariano Fortuny, arte, ciencia y diseño, Madrid, 2012, 123-159.

${ }^{30} \mathrm{~J}$. LAVER, Breve historia del traje y la moda, Madrid, 2017, p. 151 
al seleccionar esas ropas, formas y colores, para pasar a la historia rompiendo los moldes de la rigurosa identidad masculina aprobada por los convencionalismos de la sociedad isabelina reforzando el genio personal, y aunque fuera solo un puñado de artistas, era un grupo excepcional, del que formaba parte tanto el pintor del lienzo, Pedro Martínez de la Torre, como su modelo, el también artista Pedro Ximénez Mazzuco.

Dos retratos cierran este estudio sobre la relación entre moda y retrato en la España del siglo XIX (Fig. 7). Pero antes de estudiarlos, hemos de aceptar los planteamientos que hace años sostenían Galienne y Pierre Francastel en su trabajo sobre el retrato, libro esencial en la historiografía sobre ese género pictórico (1969). En él consideraban que el verdadero retrato nace en el momento en que Goya separa el individuo del fondo, el rostro de la composición compleja: "la personalidad aparece acentuada tanto por el gesto como por los rasgos del rostro" ${ }^{\prime 31}$. Los que ahora proponemos son dos autorretratos; el primero el que efectuase el pintor José Jiménez Aranda (Sevilla, 1837-1903), pintado hacia 1870, y segundo el de Gustavo Bacarisas (Gibraltar, 1873-Sevilla, 1971), de 1902, ambos conservados en el Museo de Bellas Artes hispalense.

Lo que caracteriza estos lienzos no es la forma de vestir, sino la actitud. El primero de los autorretratos revela aún el carácter romántico, en el que Jiménez Aranda se aleja un tanto del purismo académico aprendido junto a Eduardo Cano de la Peña y se muestra a sí mismo en un formato oval sobre un fondo de paisaje con los tonos violáceos de la luz del atardecer formado por un conciso paisaje de arboleda tratado de forma moder-

${ }^{31}$ G. y P. FRANCASTEL, El retrato, Madrid, 1995, p. 194. En este libro, las consideraciones acerca del retrato en el siglo XIX están centradas en torno a esa idea, es decir, el protagonismo del personaje. Ese argumento sería el que distingue el género a partir de entonces, separando al individuo de la función del contexto como vehículo de comunicación.

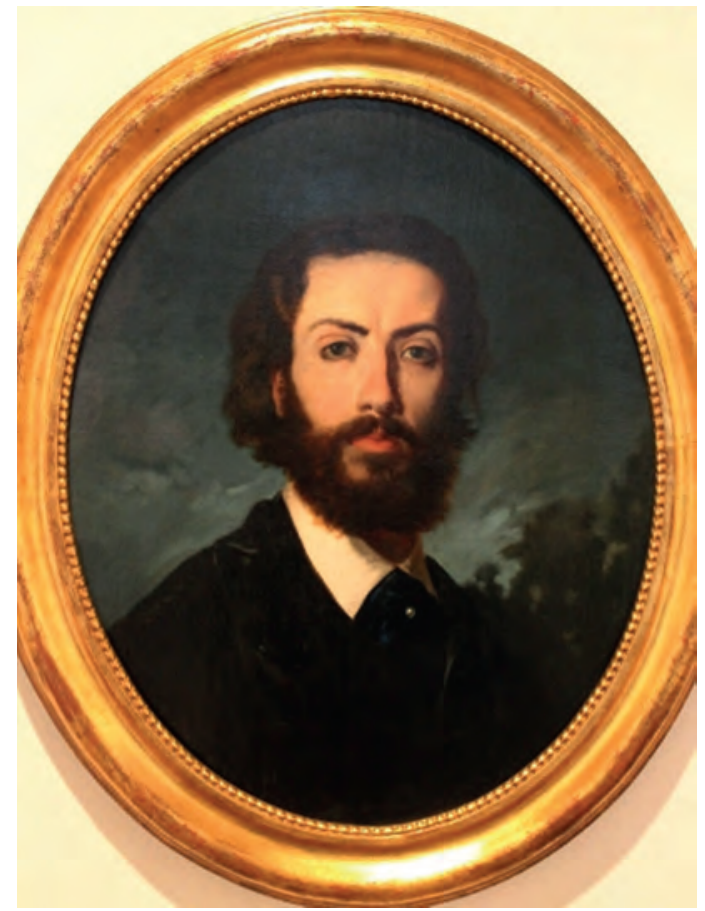

- Fig. 7. José Jiménez Aranda. Autorretrato. Ca. 1870. Museo de Bellas Artes de Sevilla. Foto del autor.

na, apenas como manchas de color ${ }^{32}$. Dicho concepto, que se impondría entre los "impresionistas" españoles décadas después, hacia 1870 era un atrevimiento que rompía con los fondos de paisaje para el gusto del romanticismo tardío; por otro lado, como pintor, reforzaría sus intereses en Roma, a partir de 1871, en contacto con Mariano Fortuny. La cuestión es que su ruptura con el "contexto" del lienzo, y siguiendo lo que indicaban los Francastel, vendría auspiciado por su deseo de resaltar el gesto $y$, sobre todo, la intensa mirada. El cabello lacio, natural y de melena corta, así como una barba media y un tanto descuidada, denotan un espíritu joven e innovador. Sin embargo, el contraste de la chaqueta negra sobre una camisa de cuello en pico y corbata azul con prendedor de perla, revela al hombre discreto, que asume la moda del vestir y la actitud del momento. Jiménez Aranda muestra, por tanto, un equi-

\footnotetext{
${ }^{32}$ Se considera una obra hacia 1870 , cuando contrajo matrimonio con su esposa. E. de PANTORBA, El pintor Jiménez Aranda. Ensayo biográfico y crítico, Madrid, 1972, p. 18. También es interesante el estudio de G. PÉREZ CALERO, José Jiménez Aranda, Sevilla, 1982.
} 
librio perfecto entre tradición y modernidad, tradición en el vestir y modernidad en su cabello y actitud. Es un bohemio domesticado, de rasgos muy realistas que lo alejan del romanticismo estricto pero que no adquiere la osadía que hemos visto en autorretratos anteriores. La novedad se halla en que confía todo el lenguaje de comunicación a su aspecto físico y la esperanza de ser comprendido por su tiempo y por el futuro en su propia dualidad.

El segundo autorretrato lo firma Gustavo Bacarisas en Roma el año $1902^{33}$ (Fig. 8). Como en el caso anterior, la fuerza expresiva del óleo se halla en la optimista e intensa mirada de un joven que se afirma a través del retrato. Bacarisas, después de una primera formación en Gibraltar, partió becado hacia Roma en 1892, contactando con el entorno de pintores españoles que allí residían y donde el recuerdo de Mariano Fortuny era muy notorio entre los jóvenes, ya fuesen paisajistas o retratistas ${ }^{34}$. La acumulación de circunstancias pudo propiciar este tipo de retrato, aún impregnado de un concepto donde el vestir discreto se ve compensado con la frescura del rostro. La identidad masculina ya no se ampara en la contraposición de la fuerza viril con lo femenino, sino en los sagrados valores de la sociedad burguesa de finales de siglo, donde la integridad moral del hombre se expresa en la obra artística. En este sentido, y como apunta Carlos Reyero, el realismo pictórico fue un gusto y estética regeneradora en cuanto animaba a profundizar en los sentimientos auténticos de los que participaba el hombre, pues él poseía el papel dominante en la construcción social ${ }^{35}$.

\footnotetext{
${ }^{33}$ Nos llama la atención que uno de los estudiosos de su obra, Manuel Castro Luna, no lo cite en su monografía sobre el artista. Quizás se deba a una recepción tardía por el museo sevillano con respecto a la publicación de la obra. M. CASTRO LUNA, Gustavo Bacarisas (1872-1971), Sevilla, 2005.

${ }^{34}$ Ibídem, pp. 48-51.

${ }^{35}$ C. REYERO, Op. cit., pp. 46-47.
}

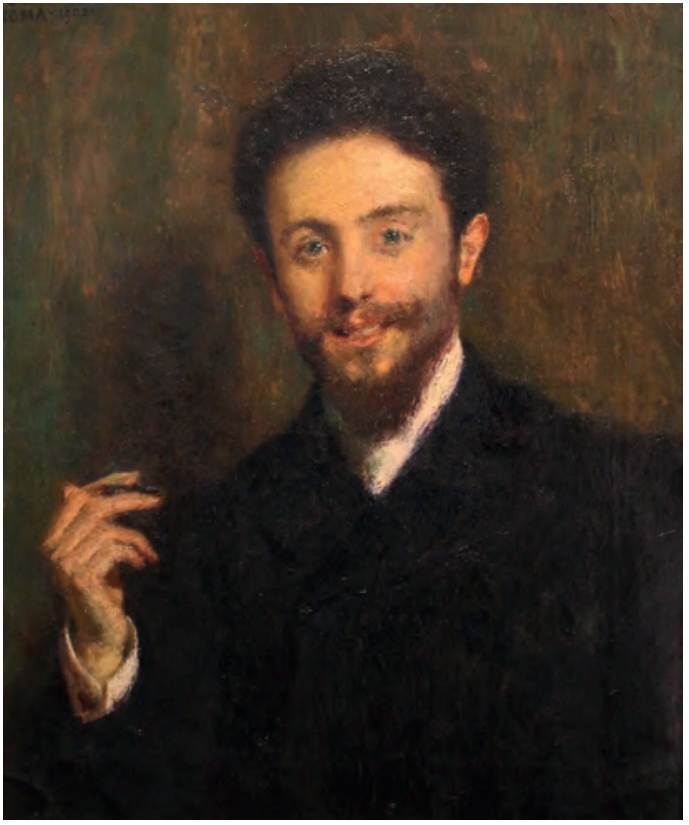

- Fig. 8. Gustavo Bacarisas. Autorretrato. 1902. Museo de Bellas Artes de Sevilla. Foto del autor.

\section{CONCLUSIONES}

Podemos concluir que en la construcción de la identidad masculina, la moda, más allá de ser un hecho en sí mismo en cuanto a fuente de estudio, constituye uno de los ejes vertebradores del relato personal, porque elegir la indumentaria, siguiendo o no los patrones de la moda, revela una forma de ser, sentir y estar. El hombre, y como hemos visto, los artistas, no son ajenos a este hecho aunque en ocasiones la historiografía del arte no repare en ello. Hemos aportado varios ejemplos del siglo xIX que contemplan la creación del retrato como un discurso propio, individual, donde la indumentaria, siguiendo o no la moda del momento, es el eje vertebrador del lienzo; más allá de los valores formales, estilísticos o la importancia de cada cuadro en la trayectoria del artista, el discurso de la moda unido al lenguaje de los gestos es la sustancia del cuadro, y no olvidemos que muchos de los lienzos propuestos en este trabajo son autorretratos; es decir, que el artista ha podido escoger una indumentaria concreta para proyectar su imagen y dirigirla al futuro. Por lo tanto, este trabajo habla del género del retrato, pero también 
habla de moda. Así pues, la moda es una de las artes de la comunicación; la posteridad se nutre de imágenes que construimos, más o menos conscientemente, a través de la moda. Y la moda no solo afecta a la indumentaria, afecta al peinado, la barba, el gesto, la mirada. Todo ello es moda y todo ello forma una parte indispensable de la historia del arte.

\section{BIBLIOGRAFÍA}

ÁLVAREZ-QUIÑONES SANZ, P., Dandis, príncipes de la elegancia, Junta de Castilla y León, 2013.

BALZAC, H., Tratado de la vida elegante, Madrid, 2011.

BANDA Y VARGAS, A. del, "El academicismo en las artes figurativas gaditanas", Archivo Español de Arte, 226, 1984, pp. 129140.

CASTRO BRUNETTO, C. y MARTÍN LÓPEZ, D., "Elegantes, casi dandis, en la plástica canaria (1800-1950)”, Estudios Canarios. Anuario del Instituto de Estudios Canarios, $\mathrm{n}^{\circ}$ 58, 2014, pp. 103-129.

CASTRO LUNA, M., Gustavo Bacarisas (18721971), Sevilla, 2005.

CERRILLO RUBIO, L., La moda moderna. Génesis de un arte nuevo, Madrid, 2010.

CLARKE, K., Beards, an unshaved history, Berlin, 2015.

FRANCASTEL, G. y P., El retrato, Madrid, 1995.

FUENTE MUÑOZ, M., “Aportaciones documentales sobre una familia de artistas: los Ferrant", Goya. Revista de Arte, no 285, 2001, pp. 356-367.

GALÁN, E. V., Pintores del Romanticismo andaluz, Granada, 1994.

GARCÍA CORTÉS, J.M., Hombres de mármol, Barcelona-Madrid, 2004.

GAVARRÓN, L., La mística de la moda, Valencia, 2003.
HERNÁNDEZ PERERA, J., “Los retratos reales de Luis de la Cruz y Ríos", Anuario de Estudios Atlánticos, nº 1, 1955, pp. 201254.

HERNÁNDEZ SOCORRO, M. R., "Rostros del ayer. Apariencias de presente: el retrato del siglo xIX en Canarias", en J. ALLEN (com.), Rostros de la Isla. El arte del retrato en Canarias [1700-2000], Las Palmas de Gran Canaria/Santa Cruz de Tenerife, 2002, p. 31-59.

LAVER, J., Breve historia del traje y la moda, Madrid, 2017.

LÓPEZ CASTÁN, A., "Las exposiciones públicas de los productos de la Industria Española y las artes decorativas en el Madrid fernandino", Anuario del Departamento de Historia y Teoría del Arte de la Universidad Autónoma de Madrid, no 3, 1991, pp. 125-137.

OSMA, G. de, Mariano Fortuny, arte, ciencia y diseño, Madrid, 2012.

PANTORBA, E. de, "Antonio María de Esquivel", Arte Español. Revista de la Asociación Española de Amigos del Arte, año XLII. XVII de la $3^{\mathrm{a}}$ época, T. XXII, 1958, pp. 155179.

PANTORBA, E. de, El pintor Jiménez Aranda. Ensayo biográfico y crítico, Madrid, 1972.

PÉREZ CALERO, G., José Jiménez Aranda, Sevilla, 1982.

PÉREZ CALERO, G., “Consideraciones estéticas en torno a la obra del pintor Antonio M. Esquivel", Laboratorio de Arte, 24, 2012, pp. 527-535.

REYERO, C., Apariencia e identidad masculina: de la Ilustración al decadentismo. Madrid, 1999.

RODRÍGUEZ PAZ, D., “Dionisio Fierros, pintor burgués", Revista da Faculdade de Letras. Ciências e Técnicas do Patrimônio, Vol. IX-XI, 2010-2012, pp. 108-126.

RODRÍGUEZ PAZ, D., “El pintor ante su imagen: una aproximación a la obra de Dionisio Fierros a través de sus autorre- 
tratos", en Mirando a Clío. El arte español espejo de su historia, Santiago de Compostela, 2012, pp. 576-590.

RUMEU DE ARMAS, A., Luis de la Cruz y Ríos, Biblioteca de Artistas Canarios no 33, Islas Canarias, 1997.

SQUICCIARINO, N., El vestido habla, Madrid, 2015.
SOUSA CONGOSTO, F. de, Introducción a la historia de la indumentaria en España, Madrid, 2007.

VILLA PASTUR, J., “Dionisio Fierros Álvarez", en Pintores Asturianos, Oviedo, 1973, T. IV, pp. 21-158. 